https://doi.org/10.15407/ujpe65.9.817

M. ALEKSANDROVYCH, ${ }^{1,2}$ G. CASTANET,${ }^{1}$ S. BURIAN,${ }^{2}$ F. LEMOINE ${ }^{1}$

D. LACROIX, ${ }^{1}$ M. ISAIEV ${ }^{1}$

${ }^{1}$ Université de Lorraine, CNRS, LEMTA

(Nancy, F-54000, France)

2 Faculty of Physics, Taras Shevchenko National University of Kyiv

(64/13, Volodymyrs'ka Str., Kyiv 01601, Ukraine)

\title{
EFFECT OF SURFACE \\ NANO-TEXTURING ON WETTING \\ PROPERTIES: MOLECULAR DYNAMICS STUDY ${ }^{1}$
}

\begin{abstract}
Molecular dynamics simulations describing the equilibrium shape of a nanodroplet located on the solid substrate are presented for the cases of a "cylindrical water droplet" on silicon substrates. Several examples of the structuration of the solid substrate surface are simulated, i.e.: atomistic flat substrate and substrates with ordered nanopillars and nanopores. The adhesives forces between molecules of the substrate and the fluid are modified to change the wettability. Three wetting configurations are considered in this work for the smooth surface: (i) hydrophilic $\left(\theta=30^{\circ}\right)$, (ii) hydrophobic $\left(\theta=136^{\circ}\right)$, and (iii) an intermediate regime $\left(\theta=80^{\circ}\right)$. Further, the dependence of the wetting angle as a function of the surface state is studied in details for the above-mentioned configurations.
\end{abstract}

Keywords: solid/fluid interface, wetting, nanostructured surface, molecular dynamics.

\section{Introduction}

The understanding of the solid/fluid interaction is important in numerous applied physics and engineering fields. In particular, the physical insight regarding wetting properties is crucial for the fabrication of superhydrophilic or superhydrophobic surfaces. The latter are promising for the creation of self-cleaning surfaces [1], as well as for the heat and mass transfer tuning across solid/fluid interfaces [2-4]. As another important example, the impact of the wettability on the formation of nucleation sites close to the nanostructured solid/fluid interface can be mentioned [5-7].

Wetting angle $(\theta)$ is one of the important characteristics which may be a criterion for the state of wettability of a solid substrate by a liquid droplet. In practice, according to the Young equation, the wet-

(C) M. ALEKSANDROVYCH, G. CASTANET, S. BURIAN, F. LEMOINE, D. LACROIX, M. ISAIEV, 2020

ISSN 2071-0194. Ukr. J. Phys. 2020. Vol. 65, No. 9 ting angle depends on the surface tensions between different phases in contact:

$\cos (\theta)=\frac{\gamma_{\mathrm{SV}}-\gamma_{\mathrm{SL}}}{\gamma_{\mathrm{LV}}}$

where $\gamma_{\mathrm{SV}}, \gamma_{\mathrm{SL}}$, and $\gamma_{\mathrm{LV}}$ are the surface tensions between solid and vapor, solid and liquid, and liquid and vapor, respectively.

It should be noted that the consideration of the wetting of a nanostructured substrate by a nanoscale droplet is more complicated. In this case, one should account for the parameters such as line tension [8,9], size dependence of surface tension [10-13], and adsorption of atoms of a liquid on the solid surface $[14,15]$. The above-mentioned phenomena can lead to a significant modification of Eq. (1). Despite the

1 This article is dedicated to the 75 th anniversary of Academician L.A. Bulavin. 
importance of the wetting in numerous physical processes, the tuning of the wetting properties in the nanoscale is a challenging issue, and the latter should be addressed based on a strong physical background.

One of the possibilities to tune the wetting angle is based on an increase of the specific surface area of interaction through the structuration of the solid substrate. Indeed, it is well known that the structuration may lead to the superhydrophilicity [16] of hydrophilic surfaces and the superhydrophobicity [17] of hydrophobic ones. It is clear that the situation starts to be more complicated in the case of a nanostructured substrate with numerous multiscale features [18-20]. In this framework, one should consider the pinning of a three-phase contact line on the structural heterogeneities [21].

Molecular dynamics (MD) approach is a powerful simulation tool which can be useful for the gaining of a physical insight regarding wetting properties on the nanoscale [22]. This approach is based on the evolution of a system of atoms that interact, respectively, by the Newton laws. To perform the simulations, one needs to set the initial configuration of the positions of atoms, the external forces, and the forces resulting from interatomic interactions.

However, MD massively consumes computational resources. Therefore, there are some limitations regarding the system sizes and/or duration of simulations. From this point of view, it is possible to partially overcome this issue with the use of different coarse-grained approaches, which are based on considerations of several atoms as one site [23], but it requires an appropriate model to be representative of the studied properties.

In this study, we will consider features of the wetting of a nanostructured surface by a liquid. The chosen surface is a monocrystalline silicon substrate with several kinds of structuration. Hereafter, we consider the cases of (i) atomically flat substrates; (ii) substrates with rectangular pillars, and (iii) substrates with rectangular pores. As a liquid, water represented by the coarse-grained ELBA model [24] is considered. Several wetting regimes (hydrophobic, hydrophilic, and neutral, respectively) for a smooth substrate are achieved changing the parameters of interaction between atoms of silicon and sites of water. The dependence of the wetting angle for such regimes was analyzed as a function of the substrate morphology.

\section{Details of Simulations}

\subsection{Interaction potentials}

As mentioned above, the ELBA coarse-grained model [23] for the simulations of interactions between water sites was used. According to this model, a water molecule is represented by one site. Thus, the longrange Coulombic interaction between atoms of water molecules can be replaced by the dipole interactions between the sites. In such way, it is possible to significantly reduce the computational time [25]. The potential of interaction between $i$ and $j$ water sites can be represented in the following form:

$U_{i j}=U_{i j}^{\mathrm{LJ}}+U_{i j}^{\mu \mu^{\prime}}$

where $U_{i j}^{\mathrm{LJ}}$ is the term describing the Lennard-Jones interactions, and $U_{i j}^{\mu \mu^{\prime}}$ is the term related to the dipole-dipole interactions. The form of the terms and the values of parameters were taken from [24]. The interactions between silicon atoms were taken according to the Stillinger-Weber potential [26]. Interactions between silicon atoms and water sites were determined by a Lennard-Jones potential

$U_{\mathrm{WSi}}=4 \varepsilon_{\mathrm{WSi}}\left[\left(\frac{\sigma_{\mathrm{WSi}}}{r_{i j}}\right)^{12}-\left(\frac{\sigma_{\mathrm{WSi}}}{r_{i j}}\right)^{6}\right]$,

where $\varepsilon_{\mathrm{WSi}}$ and $\sigma_{\mathrm{WSi}}$ are energetic and geometric parameters ofthe Lennard-Jones potential, respectively. For the evaluation of the geometric parameter, the Lorentz-Berthelot mixing rule was used:

$\sigma_{\mathrm{WSi}}=\frac{\sigma_{\mathrm{WSi}}+\sigma_{\mathrm{WW}}}{2}$.

In addition, it should be noted that, given the complex nature of interactions, it is more practical to adjust the value of the energy parameter based on considerations of the contact angle on a flat or corrugated substrate $[8,9]$. Thus, $\varepsilon_{W S i}$ was considered as a variable to set different wetting regimes.

\subsection{Initial configurations of the studied systems}

Cylindrical cap droplets located on several types of a silicon substrate are considered. In respect to this geometric configuration, the computational domain was chosen as a parallelepiped with lengths in the $\mathrm{X}, \mathrm{Y}$, and $\mathrm{Z}$ directions, respectively, to be

ISSN 2071-0194. Ukr. J. Phys. 2020. Vol. 65, No. 9 
$50 a_{0} \times 20 a_{0} \times 38 a_{0}$, where $a_{0}=5.43 \AA$ is the silicon lattice parameter. As an atomically flat surface, the monocrystalline silicon slab with diamond-type lat-

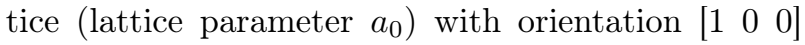
was chosen. In the $\mathrm{X}$ and $\mathrm{Y}$ directions, the size of the silicon slab was set to cover the whole domain of simulations. The thickness of the slab in the $\mathrm{Z}$ direction was equal to $8 a_{0}$, and its origin was located in the simulation domain bottom (see Fig. 1). The atoms in the bottom layer (XY plane) were fixed to the initial position with harmonic forces to prevent a vertical artificial displacement of the system. The number of silicon atoms for a flat substrate was equal to 66000 .

Additionally, the cases of a porous substrate and a substrate with nanopillars were considered. These structures were formed by deleting atoms from the initial slab. In all our simulations, the depth of pores, as well as the height of pillars, was set to $h=a_{0}$. The distance between nanopillars and pores was also the same in all simulations $\left(d=5 a_{0}\right)$. The pores and the pillars have the square cross-section with the side length equals to $l$. Additionally, it should be noted that atoms were deleted in such way that the middle of pillars and pores (in the $\mathrm{X}$ and $\mathrm{Y}$ directions) was located at the simulation domain center (see Fig. 2).

The slab of water was simulated also as a rectangular parallelepiped with the edges parallel to the X, $\mathrm{Y}$, and $\mathrm{Z}$ axes. It was located on the top of the silicon surface centered in the $\mathrm{X}$ direction and filled all space of the simulation domain in the $\mathrm{Y}$ direction (see Fig. 1). The volume of the parallelepiped was filled by water sites according to a cubic lattice. The lattice parameter was set to be equal to $3.1 \AA$ to represent the density of a bulk water. Water volume lengths were, respectively, set to $62 \AA \times 105.4 \AA \times 62 \AA$ in the $X, Y$, and $Z$ directions in the initial stage. The number of water sites was equal to 7875 , and it was constant for all simulations.

\subsection{Simulation procedure}

All MD simulations were carried out with Largescale Atomic Molecular Massively Parallel Simulator (LAMMPS) [27]. Periodic boundary conditions were set in all directions. The initial velocities among atoms were distributed on the basis of a Gaussian law to achieve the temperature equals to $1 \mathrm{~K}$. Then the system was evaluated in the NVE (constant number of particles, volume, and energy) ensemble to up-

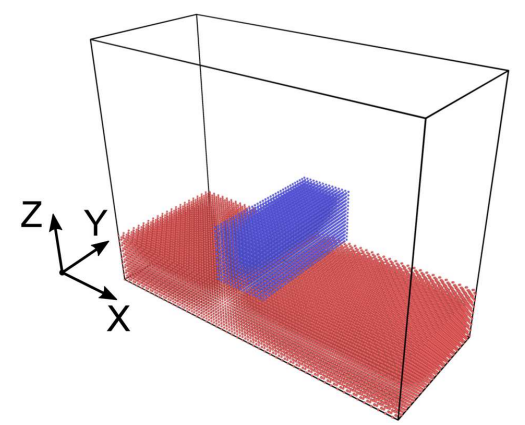

Fig. 1. Initial configuration for a droplet located on the atomistic smooth silicon surface

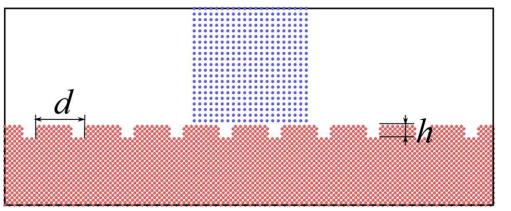

$a$
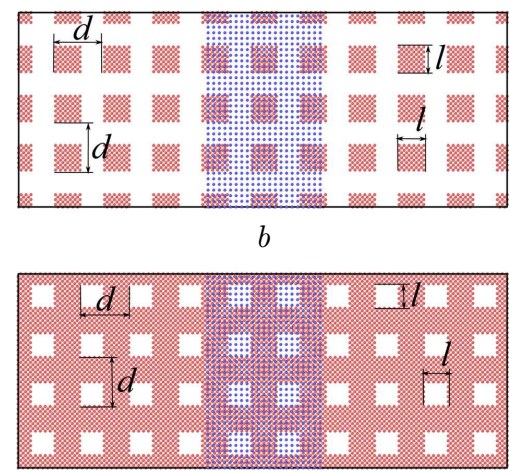

$c$

Fig. 2. Initial configurations for a nanostructured silicon surface: XZ projection for a substrate with nanopillars $(a)$; XY projection for a substrate with nanopillars $(b)$; XY projection for a porous substrate $(c)$. Only regions of interest are plotted

date velocities, positions of atoms, and the orientation of dipoles during 10000 steps with a time step of $1 \mathrm{fs}$. Simultaneously, after each time step, the energy of the system was updated to obtain the equilibrium temperature equals to $300 \mathrm{~K}$ by re-scaling the velocities. Then the system was additionally equilibrated in the NVE ensemble during 50 ps with the use of a Langevin thermostat keeping the temperature equals to $300 \mathrm{~K}$. After this procedure, the system was analyzed during 2 ns. During this period, the center of mass of a droplet was fixed in the $\mathrm{X}$ and $\mathrm{Y}$ directions to prevent smashing the wetting angle due to 




$a$

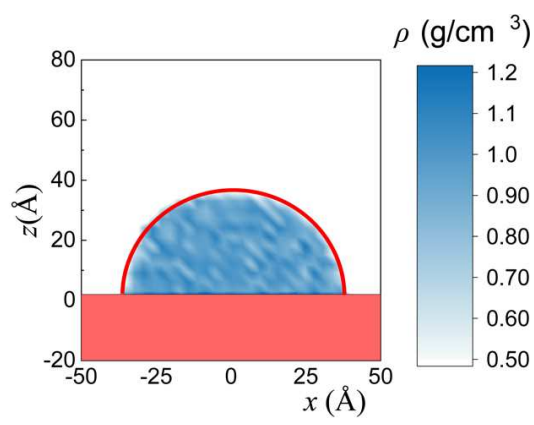

$b$
Fig. 3. Molecular dynamics snapshots of atoms' positions in the thermalized system: in the top, the projection in the XZ direction, in the bottom perspective view $(a)$; density profile of a water droplet on a silicon substrate. The solid line corresponds to the evaluated droplet shape $(b)$

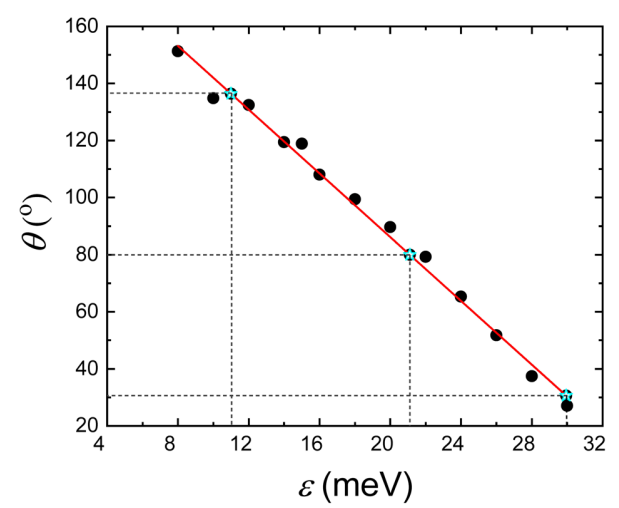

Fig. 4. Dependence of the wetting angle on the energy parameter $\left(\varepsilon_{\mathrm{WSi}}\right)$ of the Lennard-Jones potential

the translational movement of a droplet. Each 10 ps, the position of atoms was collected as snapshots. After the first nanosecond, the two-dimensional (in the $\mathrm{X}$ and $\mathrm{Z}$ directions) maps of density profiles were also collected and averaged each 0.1 ps with 10000 time steps for the evaluation of the wetting angle. As an example, Fig. 3 shows a snapshot and a density profile of water on the atomistic smooth substrate. The wetting angle was calculated with the procedure described in $[9,28]$. In addition, the equimolar lines were plotted for the density variation corresponding to a half of the bulk water density.

\section{Results and Discussions}

\subsection{Droplet on the atomistically flat substrate}

As mentioned above, the interaction potential is tuned at the initial stage by changing the value of
$\varepsilon_{\mathrm{WSi}}$ term of the Lennard-Jones potential in Eq. (3). Figure 4 shows the wetting angle as a function of this energy parameter. Dots represent the results of MD simulations, and the solid line corresponds to the linear fit. As one can see, the dependence is linear, and it can be easily used for the estimation of the energy parameter based on measurements of the wetting angle.

In order to investigate the impact of a nanostructuration on the wetting angle, three wetting configurations were distinguished: (i) hydrophilic $\left(\theta=30^{\circ}\right)$, (ii) some medium regime $\left(\theta=80^{\circ}\right)$, and (iii) hydrophobic $\left(\theta=136^{\circ}\right)$.

\subsection{Droplet on a nanostructured substrate}

Figure 5 presents the dependence of the wetting angle on the substrate roughness $R$ defined by the ratio between the top surface and projected surface. For a porous substrate, it was estimated as follows:

$R=\frac{h l^{2}}{d^{2}}$

and, respectively, for a substrate with pillars:

$R=\frac{h\left(d^{2}-l^{2}\right)}{d^{2}}$

It is important to note that there are some values of the wetting angle which are the same for the closest (in Fig. 5) neighboring points with different roughness, because of a finite size of the crystalline lattice.

As one can see from Fig. 5, $a$ and $b$, there is a general trend of increasing the "phobicity" and "philicity" by increasing the roughness in the hydrophobic and hydrophobic regimes, respectively. Specifically, there is a tendency of decreasing (increasing) the wetting angle for a hydrophilic (hydrophobic) substrate, as the roughness increases. Nevertheless, there are some irregularities and deviations from these trends. The latter can be explained by the pinning of the contact line at the pores (respectively, pillars) edges and, as a result, by the presence of the contact angle hysteresis. The most significant jumps arise, when the size of a structural feature is compatible with the droplet size. The impact of the contact line on the wetting angle can be stated also from the difference between curves corresponding to the porous substrate and the substrate with pillars. In this case, even for the same specific surface area or roughness, the droplet exhibits 


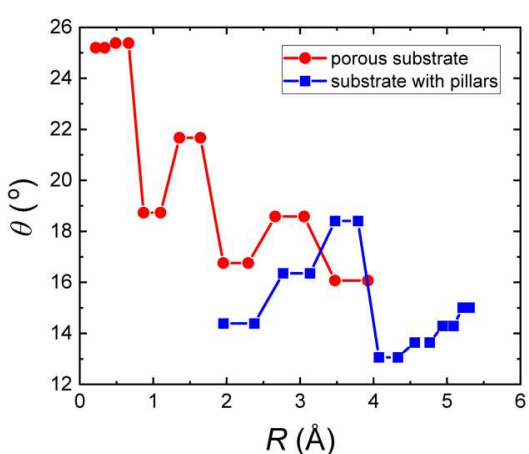

$a$

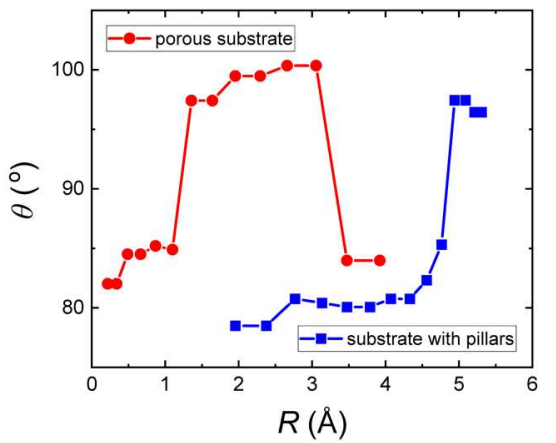

$b$



$c$

Fig. 5. Dependence of the wetting angle on the roughness for different initial wetting angles: hydrophilic $\theta=30^{\circ}(a)$; mixed $\theta=80^{\circ}(b)$; and hydrophobic $\theta=136^{\circ}(c)$

a difference in the contact line patterns (see Fig. 2, $b$ and $2, c)$. This difference leads to a difference in values of the contact angle, as well as in the curve shapes.

It is also important to note that, for the initial wetting angle $\left(\theta=80^{\circ}\right)$, the substrate may manifest hydrophilic, as well as hydrophobic properties. The latter depend on the specific surface area of contacting interfaces and on the effectiveness of the filling of pores.

\section{Conclusions}

Features of wetting properties of a nanostructured surface are studied with the use of molecular dynamics. As a result of the simulation, it is observed that the texturing of a hydrophilic (hydrophobic) surface leads to an expected change of the hydrophilicity (hydrophobicity). For a droplet deposited on a substrate exhibiting the angle close to $90^{\circ}$ before the texturing, both hydrophilic and hydrophobic behaviors can be achieved after the texturing. The latter are defined by the specific surface and the effectiveness of the water pore filling. Additionally, the strong impact of the pinning effect which is characterized by jumps in the wetting angle was observed. The jump amplitude is strong, when the drop size is comparable to the length-scale of the substrate patterns.

The publication contains the results obtained in the frames of the project ANR-19-CE09-0003. This work has been partially funded by the CNRS Energy unit (PEPS Cellule ENERGIE 2019) through the project ImHESurNaASA. The authors want also to acknowledge the partial financial support of the scientific pole EMPP of University of Lorraine. The authors thank the mesocenter EXPLOR of the Université de Lorraine and National Computing Center for Higher Education (eDari project A0080907186) for providing computational facilities. We appreciate the program of the Lorraine Université d'Excellence (LUE) for the funding of a master internship of $M A$. SB wants to acknowledge the financial support of the Ministry of Education and Science of Ukraine through the project "Features of photothermal and photoacoustic processes in low-dimensional silicon-based semiconductor systems" (State registration number 0118U000242).

1. S.S. Latthe, R.S. Sutar, V.S. Kodag, A.K. Bhosale, A.M. Kumar, K.K. Sadasivuni, R. Xing, Sh. Liu. Selfcleaning superhydrophobic coatings: Potential industrial applications. Progress in Organic Coatings. 128, 52 (2019).

2. E.A. Chinnov, E.N. Shatskiy, V.V. Semionov. Effect of thermocapillary instability on liquid film breakdown. Intern. J. Heat and Mass Transfer 145, 118692 (2019).

3. N. Wu, L. Zeng, T. Fu, Z. Wang, C. Lu. Molecular dynamics study of rapid boiling of thin liquid water film on smooth copper surface under different wettability conditions. Intern. J. Heat and Mass Transfer 147, 118905 (2020).

4. R. Liu, Z. Liu. Study of boiling heat transfer on concave hemispherical nanostructure surface with MD simulation. Intern. J. Heat and Mass Transfer 143, 118534 (2019).

5. R. Diaz, Z. Guo. Molecular dynamics study of wettability and pitch effects on maximum critical heat flux in evaporation and pool boiling heat transfer. Numerical Heat Transfer; Part A: Applications. 72, 891 (2017).

6. X. Yin, C. Hu, M. Bai, J. Lv. Molecular dynamic simulation of rapid boiling of nanofluids on different wetting surfaces with depositional nanoparticles. Intern. J. Multiphase Flow 115, 9 (2019). 
7. V.B. Warshavsky, T.S. Podguzova, D.V. Tatyanenko, A.K. Shchekin. Vapor nucleation on a wettable nanoparticle carrying a non-central discrete electric charge. J. Chem. Phys. 138, 194708 (2013).

8. M. Barisik, A. Beskok. Wetting characterisation of silicon (1,0,0) surface. Molecular Simulation. 39, 700 (2015).

9. M. Isaiev, S. Burian, L. Bulavin, M. Gradeck, F. Lemoine, K. Termentzidis. Efficient tuning of potential parameters for liquid-solid interactions. Molecular Simulation 42, 910 (2016)

10. H.G. Ozcelik, A.C. Ozdemir, B. Kim, M. Barisik. Wetting of single crystalline and amorphous silicon surfaces: effective range of intermolecular forces for wetting. Molecular Simulation 46, 224 (2020).

11. S. Burian, M. Isaiev, K. Termentzidis, V. Sysoev, L. Bulavin. Size dependence of the surface tension of a free surface of an isotropic fluid. Phys. Rev. E 95, 062801 (2017).

12. S.S. Rekhviashvili, E.V. Kishtikova. On the size dependence of a contact angle. Protection of Metals and Phys. Chem. Surfaces 48, 402 (2012).

13. S. Rekhviashvili, A. Sokurov. Modeling of a sessile droplet with the curvature dependence of surface tension. Turkish J. Phys. 42, 699 (2018).

14. M. Isaiev, S. Burian, L. Bulavin, W. Chaze, M. Gradeck, G. Castanet, S. Merabia, P. Keblinski, and K. Termentzidis. Gibbs adsorption impact on a nanodroplet shape: Modification of Young-Laplace equation. J. Phys. Chem. B 122, 3176 (2018).

15. D.V. Tatyanenko, A.K. Shchekin. Thermodynamic analysis of adsorption and line-tension contributions to contact angles of small sessile droplets. Colloid J. 81, 455 (2019).

16. T.A. Otitoju, A.L. Ahmad, B.S. Ooi. Superhydrophilic (superwetting) surfaces: A review on fabrication and application. J. Industrial and Engineering Chemistry 47, 19 (2017).

17. M. Ma, R. M. Hill. Superhydrophobic surfaces. Current Opinion in Colloid and Interface Science 11, 193 (2016).

18. J. Wloch, A.P. Terzyk, P.A. Gauden, R. Wesolowski, P. Kowalczyk. Water nanodroplet on a graphene surface a new old system. J. Phys.: Cond. Matter. 28, 495002 (2016).

19. L. Chen, Sh.-Y. Wang, X. Xiang, W.-Q. Tao. Mechanism of surface nanostructure changing wettability: A moleculardynamics simulation. Comput. Mater. Sci. 171, 1092233 (2020).

20. J. Wu, I. Snustad, A. Ervik, A. Brunsvold, J. He, Zh. Zhang. $\mathrm{CO}_{2}$ wetting on pillar-nanostructured substrates. Nanotechnology 1, 1 (2020).
21. S. Khan, J.K. Singh. Wetting transition of nanodroplets of water on textured surfaces: a molecular dynamics study. Molecular Simulation 40, 458 (2014).

22. M. Isaiev, G. Castanet, M. Gradeck, F. Lemoine, K. Termentzidis. Microscopic study of solid/fluid interface with molecular dynamics. Modern Problems of the Physics of Liquid Systems, Springer Proceedings in Physics 223, 73 (2019).

23. K.R. Hadley, C. McCabe. Coarse-grained molecular models of water: A review. Molecular Simulation 38, 671 (2012).

24. M. Orsi, J.W. Essex. The ELBA force field for coarse-grain modeling of lipid membranes. PLoS ONE 6, e28637 (2011).

25. W. Ding, M. Palaiokostas, M. Orsi. Stress testing the ELBA water model. Molecular Simulation 42, 337 (2016).

26. F.H. Stillinger, T.A. Weber. Computer simulation of local order in con- densed phases of silicon. Phys. Rev. B 31, 5262 (1985).

27. S. Plimpton. Fast parallel algorithms for short-range molecular dynamics. J. Comp. Phys. 117, 1 (1995).

28. P. Bryk, E. Korczeniewski, G.S. Szymański, P. Kowalczyk, K. Terpilowski, A. Terzyk. What is the value of water contact angle on silicon? Materials 38, 13 (2020).

Received 01.04.20

М. Александрович, Г. Кастанет,

С. Бур'ян, Ф. Лемуа, Д. Лакруа, М. Ісаєв

ВПЛИВ НАНОТЕКСТУРУВАННЯ

НА ЗМОЧУВАННЯ ПОВЕРХНІ: МЕТОД

МОЛЕКУЛЯРНОЇ ДИНАМІКИ

$\mathrm{P}$ е $з$ ю м е

Робота присвячена дослідженню рівноважної форми нанокраплі, розташованої на твердій наноструктурованій підкладинці, зокрема, було розглянуто випадок "циліндричної краплі води" на кремнієвій підкладинці. Було змодельовано декілька варіантів структурування поверхні твердої підкладинки: атомістично плоска підкладинка та підкладинка з упорядкованими наностовпчиками та нанопорами. Сили адгезії між молекулами субстрату та рідини були модифіковані відповідним чином для того, щоб варіювати змочуваність. У даній роботі було розглянуто три конфігурації змочування поверхні: 1) гідрофільний $\left(\theta=30^{\circ}\right)$, 2) гідрофобний $\left(\theta=136^{\circ}\right)$, та 3$)$ проміжний режим $(\theta=$ $\left.=80^{\circ}\right)$. В подальшому залежність кута змочування від функції стану поверхні детально вивчалась для вищезгаданих конфігурацій. 